\title{
Diarreia crônica no idoso
}

Sender Jankiel Miszputen

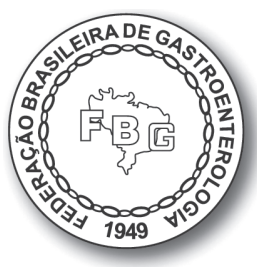

\section{INTRODUÇÃO}

Diarreia de evolução prolongada é uma manifestação clínica relativamente frequente, que se manifesta numa parcela significativa da população, secundária a distúrbios funcionais ou orgânicos, digestivos ou não digestivos. Os idosos - faixa etária acima de 65 anos - não só estão sujeitos à quase totalidade das causas que promovem alterações no comportamento intestinal observado em jovens, como acrescentam algumas outras etiologias próprias, relacionadas à idade. É difícil precisar sua prevalência, pois muitos doentes não procuram assistência médica, em razão de sintomas toleráveis que não interferem com sua qualidade de vida ou ainda porque tentam solucioná-los com medicamentos e/ou dietas, decididos por sua vontade ou sugestão leiga. Esse comportamento pode encobrir a verdadeira etiologia desta síndrome e impedir o diagnóstico da causa ou das causas e a conduta mais adequada.

\section{DEFINIÇÃO}

Clinicamente, as principais queixas estão centradas na maior frequência das evacuações e na diminuição de consistência do bolo fecal, as quais são, efetivamente, a base para se aceitar a hipótese de uma síndrome diarreica. Por outro lado, para parte dos doentes, a simples mudança na fluidez das fezes, mais amolecidas ou líquidas, mais do que a frequência, pode ser interpretada por eles como diarreia. Do ponto de vista fisiopatológico, diarreia significa um aumento no teor de água eliminada com as fezes no período de 24 horas, independentemente do número diário de evacuações. A definição mais completa 
inclui também a possibilidade da presença, no material evacuado, de muco e/ou sangue e/ou pus e de restos alimentares íntegros, que normalmente são digeridos/absorvidos pelo organismo, não se observando habitualmente sua evacuação como tal.

A frequência evacuatória é um parâmetro mais fácil de ser analisado, mas sua variabilidade também depende, em parte, do teor de fibras da dieta, que conferem ao bolo fecal, maior peso (entre 100 a $200 \mathrm{~g} /$ dia) e que colaboram com a retenção de água. De toda forma, é desejável atenção nas informações da história clínica, pois, assim como é possível suspeitar-se de uma diarreia verdadeira a partir de poucas evacuações diárias, desde que o conteúdo aquoso sugira um volume anormal, também é possível que múltiplas dejeções nem sempre se enquadrem no conceito fisiopatológico desta disfunção, caracterizando a chamada pseudodiarreia.

A maioria dos estudos define a diarreia como crônica quando ela ultrapassa o limite de 4 semanas de duração. Seu diagnóstico diferencial é vasto, mas história clínica, interrogatório, antecedentes pessoais e familiares e exame físico obtidos com detalhes e testes complementares corretamente direcionados permitem reconhecer sua origem e elaborar o plano de tratamento mais apropriado.

\section{CLASSIFICAÇÃO FISIOPATOLÓGICA DAS DIARREIAS}

Alguns mecanismos fisiopatológicos estão envolvidos no desencadeamento de diarreias, as quais podem se manifestar de forma contínua ou intermitente.

- Osmótica. Presença, na luz intestinal, de substâncias que, pelo seu poder osmótico, impedem a absorção de água e eletrólitos ou até favoreçam seu retorno do meio interno para o lúmen.

- Secretora. Aumento na secreção de íons e de água para o lúmen intestinal.

- Exsudativa. Aumento na secreção de muco e material proteico para o lúmen intestinal.

- Motora. Por hiper ou hipomotilidade intestinal.

\section{ETIOLOGIA DE ACORDO COM O MECANISMO FISIOPATOLÓGICO}

\section{Osmótica}

O intestino delgado não convive, fisiologicamente, com diferenças osmóticas entre o conteúdo luminal e o meio interno. A absorção de nutrientes 
pelo jejuno acaba transferindo água para o compartimento intracelular, conseguindo manter a osmolaridade equilibrada entre os dois ambientes. Essa condição será rompida caso permaneçam, no lúmen, substâncias osmoticamente ativas, que não só irá reter como poderá redirecionar água já incorporada de volta para o lúmen. As causas mais frequentes de diarreia osmótica no idoso são:

- Intolerância à lactose: naturalmente, no idoso, ocorre redução gradual da produção de enzimas responsáveis pela digestão dos carboidratos, principalmente a lactase. A intolerância para laticínios mais ricos em lactose pode não ser identificada pelo doente, devendo, portanto, ser computada pelo médico no diagnóstico diferencial. Caso já exista a suspeita, recomenda-se sua comprovação laboratorial ou por meio de teste dietético com restrição dos produtos que contenham esse açúcar.

- Intolerância à frutose: menos frequente e mais difícil de ser reconhecida pelo doente. Alimentos com alta concentração de frutose ultrapassam a capacidade absortiva intestinal do açúcar promovendo meteorismo e diarreia. Da mesma forma que na intolerância à lactose, teste laboratorial ou restrição de produtos com maior teor de frutose permitem diagnosticar essa etiologia para a queixa diarreica.

- Má digestão ou absorção de nutrientes: doenças pancreáticas crônicas, obstrução ductal, atrofia e ressecções cirúrgicas que reduzam a secreção exócrina da glândula provocam insuficiente digestão de todos os alimentos e, consequentemente, hiperosmolaridade do conteúdo luminal; o mesmo ocorre em relação às gorduras, por inadequada produção ou excreção de sais biliares nas hepatopatias ou colestases intratáveis ou aumento de sua perda pelas fezes em razão de doenças do íleo distal, sítio de sua reabsorção e na ressecção desse segmento. Enterectomias proximais ou ressecções extensas, que no idoso podem seguir quadros isquêmicos mesentéricos ou tumorais, diminuem a área intestinal, provocando má digestão e/ou má absorção dos nutrientes.

- Sobrecrescimento bacteriano: hipo ou anacloridria (atrofia gástrica, medicamentos, gastrectomia) e condições para hipomotilidade intestinal (neuropatia diabética, esclerodermia, hipotireoidismo, doença de Parkinson) aumentam a possibilidade para a proliferação de microrganismos no jejuno, cujas enzimas competem com aquelas das microvilosidades dos enterócitos, resultando também na má digestão e má absorção de nutrientes. Esses produtos bacterianos desconjugam os sais biliares, afetando a micelação das gorduras dos alimentos e sua consequente má absorção. Sobrecrescimento também é observado na diverticulose do intestino delgado e nas situações 
de estase provocadas por aderências pós-operatórias abdominais e suboclusões crônicas. Embora não seja propriamente caso de sobrecrescimento, a remoção da válvula ileocecal facilita o acesso da microbiota às porções mais altas do delgado, com todas as mesmas consequências.

- Infecciosas: a doença de Whipple, de origem bacteriana (Tropheryma whipplei) e parasitoses maciças (giardíase, estrongiloidiase) de alguma forma relacionadas ao estado imunológico do doente, cujo comprometimento não é tão infrequente no idoso, têm sua instalação facilitada, provocando diarreias demoradas e consumptivas, a primeira por alterar o transporte pós-epitelial dos nutrientes, e a segunda por roubarem superfície absortiva.

\section{Secretora}

Os tumores neuroendócrinos promovem hipersecreção de hormônios ou de neuromoduladores, ocasionando significativa perda intestinal de água e eletrólitos. São exemplos o gastrinoma (Zollinger-Ellison), o vipoma pancreático (Verner-Morrison), o tumor carcinoide (serotonina), os produtores de somatostatina, glucagon, prostaglandinas e o tumor tireoidiano secretor de calcitonina.

\section{Exsudativa}

É igualmente uma diarreia secretora, diferenciada pelo tipo do material secretado: proteínas e muco.

- Inflamatória: embora não seja a faixa etária de incidência preferencial, uma parcela não desprezível de idosos inicia queixa diarreica de longa duração, decorrente de retocolite ulcerativa ou doença de Crohn. Essa relativa raridade traz algum retardo no diagnóstico, pois outras etiologias ganham prioridade no diagnóstico diferencial, como o câncer de cólon e linfomas do intestino delgado, que também cursam com um componente inflamatório exsudativo.

- Actínica: as sequelas de irradiação ionizante na área abdominal ou pélvica, enterites e colites actínicas, que ocorrem em cerca de $20 \%$ dos casos que passaram por esse tratamento, são representadas por um processo inflamatório crônico, até criando alguma atrofia das estruturas digestivas atingidas e alterações circulatórias isquêmicas irreversíveis. 
- Infecciosa: algumas infecções bacterianas têm curso prolongado e também se aproveitam da deficiência imunológica dos gerontes, como a tuberculose e a menos frequente produzida por Yersinia enterocolitica. A infecção pelo Clostridium difficile, adquirida muitas vezes em comunidades de idosos por transmissão interpessoal ou por uso de antibióticos ou quimioterápicos, tende a ser de evolução mais aguda, mas não raramente se prolonga, por sua difícil erradicação com os tratamentos disponíveis.

- Parasitária: o maior exemplo é a infecção por Entoamoeba histolytica, também oportunista, especialmente em áreas nas quais as condições sanitárias favorecem sua contaminação.

- Vascular: isquemias crônicas possibilitam manifestações diarreicas, pois interferem com o sistema circulatório terminal das vilosidades e no seu retorno venoso, podendo gerar dificuldades para a absorção e o transporte sanguíneo de nutrientes. Processo inflamatório também encontra-se presente no intestino isquêmico.

\section{Motora}

Tanto hiper quanto hipomotilidade intestinais são causa de diarreia de longa duração.

- Hipermotilidade: o trânsito intestinal em tempo mais rápido que o fisiológico impede o suficiente contato dos nutrientes com as superfícies entérica e colônica, não havendo tempo apropriado para sua digestão e absorção, assim como a recuperação da água, que atinge os segmentos distais em quantidade aumentada, exteriorizando-se na forma de fezes de menor consistência. Essa condição é observada em doenças como o hipertireoidismo, nos tumores neuroendócrinos e no distúrbio funcional diarreico do intestino irritável. É preciso salientar que alterações do ritmo intestinal que se iniciam no idoso requerem investigação complementar, antes de serem aceitas como funcionais. Nunca omitir o interrogatório sobre os medicamentos em uso de rotina. A polifarmácia é comum nessa faixa etária. Alguns colecistectomizados desenvolvem diarreia, provavelmente, por fluxo contínuo dos sais biliares, que têm poder laxativo.

- Hipomotilidade: a lentidão do trânsito favorece o sobrecrescimento bacteriano, com os efeitos já comentados. Algumas situações clínicas induzem a estase intestinal, como neuropatia diabética, esclerodermia, hipotireoidismo, doença de Parkinson, vagotomia, diverticulose do intestino delgado e suboclusões intestinais crônicas. 


\section{ROTEIRO DIAGNÓSTICO}

\section{História clínica}

- Tempo de duração da queixa.

- Apresentação contínua ou intermitente.

- Início abrupto ou evolução gradual.

- Características das evacuações: frequência e consistência, presença de muco/sangue ou restos alimentares, aspecto engordurado.

- Urgência e/ou incontinência fecais.

- Evacuações diurnas, noturnas ou ambos.

- Sintomas associados ou relacionados: dor abdominal, náuseas.

- Fatores de piora, alimentos (lactose, farináceos, fibras, frutas, produtos dietéticos), estresse.

- Viagens recentes.

\section{Interrogatório}

- Perda de peso.

- Medicamentos com potencial laxativo e coincidência com o início da diarreia.

Antecedentes pessoais

- Cirurgias digestivas abdominais (ressecções, aderências).

- Radioterapia sobre vísceras abdominais.

- Doenças: diabetes, hipertireoidismo, colagenoses, vasculares, alcoolismo.

Antecedentes familiares

- Neoplasia de cólon.

- Doença inflamatória intestinal.

\section{Exame físico}

- Febre, sinais de anemia e/ou desnutrição, edemas, hipotensão postural, equimoses.

- Linfonodomegalia.

- Volume tireoidiano.

- Ritmo cardíaco.

- Derrames cavitários. 
- Neuro e miopatias.

- Propedêutica abdominal: aumentos viscerais, massas palpáveis, ascite.

\section{Exames complementares}

Embora as diarreias crônicas sejam predominantemente de origem funcional e dispensem exames complementares, é preciso considerar que, no idoso, especialmente com queixas recentes, sua investigação é absolutamente indispensável. Os dados da anamnese e do exame físico já possibilitam elaborar uma hipótese diagnóstica diferencial, mas, se a opção inicial for por um teste terapêutico, recomenda-se rever o paciente após 6 semanas e avaliar o resultado do tratamento. A manutenção dos sintomas decidirá pela necessidade de procedimentos investigatórios. Mesmo para as diarreias consideradas funcionais, alguns exames laboratoriais gerais, não invasivos, podem ser solicitados de imediato, para análise de certos parâmetros e, objetivamente, compará-los com a impressão clínica inicial: hemograma (anemia); albumina (nutrição); proteína C reativa (inflamação); glicemia (diabetes insuspeito); sódio e potássio (perda fecal aumentada); $\mathrm{T}_{4}$ livre e TSH (observar outros sinais físicos de hipertireoidismo) e cálcio (hipoparatireodismo). No material fecal, recomenda-se, além do protoparasitológico, a contagem de leucócitos, pesquisa de gorduras (Sudan III) e sangue oculto (imunoquímico). A dosagem da calprotectina nas fezes pode diferenciar a diarreia funcional da secundária à inflamação ou neoplasia.

As recomendações a seguir devem ser aplicadas para os casos cuja justificativa não tenha sido reconhecida por anamnese, exame físico e laboratório geral.

\section{Anemia}

Avaliar o tipo (ferropriva, macrocítica). Investigar fatores dietéticos e bioquímicos (dosagem de ferro, ferritina, índice de saturação da transferrina, ácido fólico e vitamina B12) e, se indicada, endoscopia alta e baixa, mesmo com sangue oculto negativo. Níveis baixos de albumina, inapetência e perda de peso têm a mesma recomendação.

\section{Perda de gordura pelas fezes}

Identifica sua má digestão ou absorção, que costuma refletir o mesmo comprometimento dos demais nutrientes. A diferenciação deve ser obtida pelo teste da D-xilose, açúcar simples, cuja absorção depende exclusivamente da integridade morfofuncional da mucosa do delgado. Resultado normal remete à investigação de doenças pancreáticas, que podem ser reconhecidas por méto- 
dos de imagem [ultrassonografia (US), tomografia computadorizada (TC), ressonância magnética (RM), ecoendoscopia ou CPRE] e sua função pela dosagem fecal de elastase. D-xilose normal sugere doença da parede intestinal que será investigada, inicialmente, por procedimentos de imagem não invasivos (enterotomografia ou enterorressonância), podendo ser complementados pela endoscopia no caso de lesão difusa ou enteroscopia nas alterações localizadas, ambas com obtenção de biópsias.

Outra etiologia que origina esteatorreia é o sobrecrescimento bacteriano, cuja confirmação se obtém pelo teste respiratório, com medida do $\mathrm{H}_{2}$ expirado após sobrecarga com lactulose ou glicose.

Perda de gordura pelas fezes ocorre também quando há redução do pool total de sais biliares, produzidos pelo fígado (hepatopatias crônicas), colestases (diminuição do fluxo) e nas ressecções do íleo distal (perda fecal). Essa diminuição interfere na formação das micelas com prejuízo na digestão final e absorção de triglicerídios.

\section{Intolerância alimentar}

Tanto a da lactose como da frutose são identificadas após sobrecarga com os respectivos açúcares, de preferência pelo teste respiratório com dosagem do $\mathrm{H}_{2}$ expirado.

\section{Diarreia infecciosa}

A coprocultura clássica é um método diagnóstico difícil de interpretar, a não ser na pesquisa de microrganismos específicos, caso da Yersinia. Quanto à doença de Whipple, somente a pesquisa de macrófagos, em material de biópsia intestinal obtido por endoscopia e corado pelo PAS, permite sua confirmação.

\section{Diarreia secretora}

A dosagem de eletrólitos nas fezes é capaz de diferenciar a diarreia secretora da osmótica, ambas com grande evacuação aquosa. Medidas da concentração de $\mathrm{Na}$ e K fecais permitem o cálculo do gap osmótico, para definir o tipo secretor.

Tumores neuroendócrinos sintetizam hormônios e neurotransmissores, que estimulam o aumento da secreção de íons e água, a exceção do tumor de Zollinger-Ellison, produtor de uma substância semelhante à gastrina, responsável por grande secreção de $\mathrm{HCl}$ pelo estômago. Sua chegada ao duodeno inibe as enzimas pancreáticas digestivas, resultando em má digestão dos nutrientes, combinando assim os modelos secretor e osmótico. Dosagem sanguínea da gastrina é a orientação para o diagnóstico dessa síndrome. 
Nível aumentado da cromogranina A é indicativo para ouras dosagens sanguíneas, envolvendo polipeptídio intestinal vasoativo (vipoma), glucagon (glucagonoma) e calcitonina (tumor medular da tireoide). O carcinoide é avaliado pela medida urinária do seu metabólito, ácido 5 hidróxi-indol-acético. $\mathrm{O}$ PETscan pode ser útil na localização das lesões primárias e secundárias.

\section{Diarreia inflamatória/neoplásica}

$\mathrm{Na}$ suspeita dessas etiologias, endoscopia digestiva alta e colonoscopia devem definir o diagnóstico, seja da doença de Crohn ou retocolite ulcerativa ou de neoplasias. Como podem ocorrer inflamação ou tumores em segmentos do tubo digestivo inacessíveis a esses procedimentos, enteroscopia com biópsias, se disponível, enterotomografia ou enterorressonância são os métodos diagnósticos de escolha.

\section{Diarreia isquêmica}

Angiotomografia do território mesentérico é a investigação mais recomendada para identificar as alterações circulatórias enterocólicas.

\section{Diarreia actínica}

As sequelas de radioterapia abdominal, que podem se manifestar anos após o tratamento, podem ser identificadas por exames de imagem: colonoscopia, enteroscopia, enterotomografia ou enterorressonância. Análise histológica, quando possível, contribui para sua definição.

\section{Diarreia motora}

As alterações de hipo ou hipermotilidade devem ser estudadas por imagem, em radiografias simples de abdome em tempos pré-determinados, após ingestão de cápsula com marcadores radiopacos.

\section{Disfunções anatômicas}

Se a finalidade é somente analisar anatomicamente os segmentos remanescentes após ressecções, os clássicos exames contrastados do trânsito intestinal e enema baritado são suficientes.

\section{TRATAMENTO}

Obviamente, o tratamento das diversas etiologias da diarreia crônica deve ser particularizado. Considerar suas possíveis implicações clínicas relacionadas à idade do doente e a sobreposição com seus medicamentos de uso rotineiro. 


\section{CONSIDERAÇÕES FINAIS}

Exames gerais sanguíneos e fecais descritos anteriormente devem orientar a sequência da pesquisa da etiologia da diarreia crônica, desde que as informações da história clínica e os achados físicos não consigam já elaborar sua hipótese.

\section{REFERÊNCIAS BIBLIOGRÁFICAS}

1. Arasaradnam RP, Brown S, Forbes A, Fox MR, Hungin P, Kelman L, et al. Guidelines for the investigation of chronic diarrhoea in adults: British Society of Gastroenterology, 3rd edition. Gut. 2018;67(8):1380-99.

2. Schiller LR, Pardi DS, Sellin JH. Chronic diarrhea: diagnosis and management. Clin Gastroenterol Hepatol. 2017;15(2):182-93.

3. Schiller LR, Pardi DS, Spiller R, Semrad CE, Surawicz CM, Giannella RA, et al. Gastro 2013 APDW/WCOG Shanghai working party report: chronic diarrhea: definition, classification, diagnosis. J Gastroenterol Hepatol. 2014;29(1):6-25. 